\title{
Exploring evidence-based innovative therapy for the treatment of chronic HBV infection: experimental and clinical
}

\author{
Sheikh Mohammad Fazle Akbar ${ }^{1+}{ }^{*}$, Mamun Al Mahtab ${ }^{2 \dagger}$, Julio Cesar Aguilar ${ }^{3}$, Md. Helal Uddin ${ }^{4}$, \\ Md. Sakirul Islam Khan ${ }^{5}$, Osamu Yoshida ${ }^{1}$, Eduardo Penton ${ }^{3}$, Guillen Nieto Gerardo ${ }^{3}$, Yoichi Hiasa ${ }^{1}$ \\ ${ }^{1}$ Department of Gastroenterology and Metabology, Ehime University Graduate School of Medicine, Ehime 7910295, Japan \\ ${ }^{2}$ Department of Hepatology, Bangabandhu Sheikh Mujib Medical University (BSMMU), Dhaka 1000, Bangladesh \\ ${ }^{3}$ Center for Genetic Engineering and Biotechnology, Havana, Havana 10600, Cuba \\ ${ }^{4}$ Specialized Liver Center, Dhaka 1205, Bangladesh \\ ${ }^{5}$ Department of Anatomy and Embryology, Ehime University Graduate School of Medicine, Ehime 7910295, Japan
}

${ }^{\dagger}$ The two authors contributed equally to the work.

*Correspondence: Sheikh Mohammad Fazle Akbar, Department of Gastroenterology and Metabology, Ehime University Graduate School of Medicine, Ehime 7910295, Japan. sheikhmohammadfazle@gmail.com

Academic Editor: Amedeo Lonardo, Azienda Ospedaliero-Universitaria di Modena, Italy

Received: June 2, 2021 Accepted: August 3, 2021 Published: October 31, 2021

Cite this article: Akbar SMF, Al Mahtab M, Cesar Aguilar J, Uddin MH, Khan SI, Yoshida O, et al. Exploring evidence-based innovative therapy for the treatment of chronic HBV infection: experimental and clinical. Explor Med. 2021;2:392-409. https:// doi.org/10.37349/emed.2021.00058

\begin{abstract}
With the advent of various vaccines and antimicrobial agents during the 20th century, the control and containment of infectious diseases appeared to be a matter of time. However, studies unveiled the diverse natures of microbes, their lifestyle, and pathogenetic potentials. Since the ground-breaking discovery of the hepatitis B virus (HBV) by Baruch Blumberg and the subsequent development of a vaccine in the early 1980s, the main task of the scientific community has been to develop a proper management strategy for HBV-induced chronic liver diseases. In the early 1980's, standard interferon (IFN) induced a reduction of HBV DNA levels, followed by the normalization of serum transaminases (alanine aminotransferase, ALT), in some chronic hepatitis B (CHB) patients. However, in the course of time, the limitations of standard IFN became evident, and the search for an alternative began. In the late 1980's, nucleoside analogs entered the arena of CHB treatment as oral drugs with potent antiviral capacities. At the beginning of the 21st century, insights were developed into the scope and limitations of standard IFN, pegylated-IFN as well as nucleoside analogs for treating CHB. Considering the non-cytopathic nature of the HBV, the presence of covalently closed circular DNA (cccDNA) in the nucleus of the infected hepatocytes and HBV-induced immune-mediated liver damages, a new field of CHB management was initiated by modulating the hosts' immune system through immune therapy. This review will discuss the nature and design of innovative immune therapy for CHB.
\end{abstract}

\section{Keywords}

Chronic hepatitis B, antiviral drugs, immune therapy, therapeutic vaccine

\footnotetext{
(C) The Author(s) 2021. This is an Open Access article licensed under a Creative Commons Attribution 4.0 International License (https://creativecommons.org/licenses/by/4.0/), which permits unrestricted use, sharing, adaptation, distribution and reproduction in any medium or format, for any purpose, even commercially, as long as you give appropriate credit to the original author(s) and the source, provide a link to the Creative Commons license, and indicate if changes were made.
} 


\section{Introduction}

Hepatitis B virus (HBV) is a DNA virus belonging to the family Hepadnaviridae [1]. It infects people of all ages. $\mathrm{HBV}$ is estimated to have infected approximately two billion people worldwide at some point in their life, out of which around 250 million have been chronically infected with HBV (supports active HBV replication) with or without any evidence of ongoing liver damage. These patients are living, permanent reservoirs of HBV and are responsible for transmitting HBV to healthy non-infected individuals [2]. Although several preventive measures have been taken to contain the HBV infection, such as potent prophylactic vaccines, the world has been experiencing about 30 million new cases of HBV infection each year, the sources of which are people infected with chronic HBV [3]. Thus, the development of treatment strategies for millions of patients with chronic hepatitis B (CHB) represents a major challenge for mankind. After discovering HBV in the 1960's and the characterization of the virus in the 1970's, the history of therapeutic interventions of CHB has been highly dynamic. At least two groups of drugs have been widely used to treat CHB patients. Interferon (IFN) and its pegylated form, pegylated IFN (Peg-IFN), have been used in CHB patients since the 1980's as injectable antiviral drugs. Since the 1990's, oral nucleoside analogs (NUCs) have been used in CHB patients around the world [4]. Thus, about four decades have passed since initiating drug treatment of CHB. Although these drugs have induced benefits in some CHB patients [5], they are endowed with notable limitations, such as adverse effects, finite versus infinite treatment regimens, levels of efficacies, capacities to block progressive liver diseases such as cirrhosis of the liver (LC), hepatocellular carcinoma (HCC), and costs [6-9]. Another important factor is related to the drug treatment for CHB patients in different regions of the world. Most CHB patients reside in developing and resource-constrained countries in Asia and Africa; hence, significant limitations about compliance with infinite therapy, cost, and adverse effects remain [10].

\section{Fundamental basis of using IFN- $\alpha$ and Peg-IFN for treating CHB}

Although several notable limitations of IFN- $\alpha$ and Peg-IFN have recently been discovered in the treatment of CHB, the drugs were found to have an excellent therapeutic utility when they were initially considered for therapy. IFN and its derivative are endowed with potent antiviral activity as well as immune modulatory capacities. IFN-induced control of HBV replication is ensured by decreasing RNA transcription [11]. One area of interest regarding the role of IFN on covalently closed circular DNA (cccDNA). Of the medications currently available, only IFN- $\alpha$ can potentially target cccDNA. However, the clinical effects of eradicating cccDNA using IFN- $\alpha$ in CHB patients are neither satisfactory nor encouraging. Thus, more insights are required. IFN- $\alpha$ epigenetically regulates transcriptional activity by modulating the lysine acetyltransferase 2A (GCN5)-mediated succinylation of histone H3 on lysine 79 (H3K79) to reduce HBV cccDNA. IFN- and toll-like receptors (TLR)-mediated innate immune responses can restrict HBV replication at the different steps of the viral life cycle [12]. Moreover, there are other mechanisms that regulate cccDNA. Focus has also been given to the inhibition of HBV replication by IFN-stimulated genes and the inhibition of IFN signaling by $\mathrm{HBV}$ and viral proteins. Interferons can diminish HBV cccDNA via apolipoprotein B mRNA editing enzyme 3 (APOBEC3)-mediated deamination using the interferon-stimulated gene (ISG) pathway [13]. The underlying mechanism has been proposed to be the HBV core protein mediating the interaction with nuclear cccDNA, resulting in cytidine deamination, apurinic/apyrimidinic site formation, and, finally, the cccDNA degradation that prevents HBV reactivation [13]. IFN-alpha has shown anti-fibrotic effects, which may enhance its utility in blocking a progression to cirrhosis [14-17].

\section{Limitations of IFN- $\alpha$}

IFN- $\alpha$ exhibited considerable optimism as a therapeutic choice for CHB. However, its long-term efficacy was not sustained. In addition, the role of IFN- $\alpha$ in hepatitis B e antigen (HBeAg)-negative patients was not satisfactory [18]. Finally, IFN- $\alpha$ could neither reduce hepatitis B surface antigen (HBsAg) levels nor cccDNA to a reasonable level in most patients with CHB $[19,20]$. The limited efficacy of IFN- $\alpha$ can be attributed to its aberrant immune modulatory capacity, which induces confusing signals in IFN-users [21, 22]. 
In addition to low efficacy, IFN is not a patient-friendly drug; it is administered via injection. Moreover, drug compliance is a serious limitation in a developing and resource-constrained set-up. It is costly. As with standard IFN- $\alpha$, treatment with peginterferon is associated with many troublesome and, occasionally, serious or even life-threatening side effects. These side effects are particularly common in patients with advanced disease and hypersplenism. INF is contraindicated in patients with decompensated cirrhosis. Severe exacerbations of the disease with immediate and marked increases in serum ALT levels are common and can have devastating clinical consequences for these patients, even when the decompensation is mild and reduced doses of IFN are given [23]. When taken together, IFN therapy could not stand the test of time for the treatment of CHB patients despite initially inspiring considerable optimism.

\section{Scope of nucleoside and nucleotide analogs}

CHB poses serious concerns for different branches of medical science. The disease by itself compromises the quality of life. Furthermore, its complications shatter the social, medical, and national healthcare delivery system. The annual death toll due to HBV-related liver diseases has reached nearly one million. These factors have induced the need to search for new and novel drugs for CHB. Thus, in the 1990's, the appearance of NUCs was highly regarded in the medical community. NUCs were the first drugs against CHB that could be given orally. They were also comparatively cheaper. The development of NUCs started from lamivudine in the 1990's and continued, and new NUCs replaced older ones with better efficacy and fewer adverse effects [24-33]. NUCs exhibit potent antiviral and liver-protecting effects when used in CHB patients. Studies have shown that the usage of NUCs in CHB patients results in HBV DNA negativity in the sera in a vast majority of patients. However, logical concerns remain about the capacities of NUCs to induce negativity of HBsAg and seroconversion to antibodies to HBsAg (anti-HBs) in CHB patients. Another notable finding that recommended the usage of NUCs in CHB is related to maintaining the suppression of HBV DNA by blocking the progression of fibrosis in non-cirrhotic patients. Moreover, it has been reported that NUCs can regress fibrosis in patients with advanced fibrosis/cirrhosis. However, the risk of the development of HCC is maintained even after HBV DNA negativity by NUCs, particularly in patients with cirrhosis. One study showed that after five years of viral suppression, the risk decreased in Caucasian patients by about 50\% [34]. In the context of NUC therapy for CHB patients, it is also important to decide when NUC therapy can be ceased. In the last five to eight years, there has been cumulating evidence that NUC therapy can be discontinued in antibodies to HBeAg (anti-HBe) positive patients, without cirrhosis and with stable HBV DNA suppression and decreasing levels of HBsAg in serum. There may be a transient flare of ALT in these circumstances. This may not be clinically dangerous and may be related to the clearance of HBsAg due to the revival of host immunity. However, CHB patients should be properly monitored at this stage before cessation of NUCs [35].

Therefore, it can be said that treatment using NUCs results in the reduction or negativity of HBV DNA in the blood. HBeAg seronegative and seroconversion to anti-HBe were also reported by NUC-treated CHB patients in a different cohort. Some studies also reported on the anti-cirrhotic effect of NUCs. Even NUCs were shown to have a protective effect on HCC development. With all these positive properties, it can be assumed that a group of drugs that can manage CHB has finally been found in the early 21 st century.

\section{Limitation of NUCs}

However, the 'honeymoon period' of NUC usage for treating CHB did not last long as its limitations began to surface. NUCs turned out to be a double-edged sword. This is an infinite drug regimen; the drug has to be used for years or decades or even for life. Further, if the drug is ceased, there may be serious complications, such as a hepatic flare. Moreover, treatment with NUCs is not ideal for reducing HBsAg levels in CHB patients. Finally, NUCs have an insignificant impact on cccDNA [36-45]. Different hepatologists and professional liver organizations have provided recommendations about the logical and rational usage of NUCs. However, these recommendations may still not be properly applied in developing and poor countries that harbor the main load of global CHB patients [46-50]. 
NUCs are also endowed with considerable side effects. Some analogues exhibit activity against the human mitochondrial DNA (mtDNA) polymerase gamma, which can lead to mitochondrial dysfunction. They also induce lactic acidosis. This figure indicates that entecavir should be used with caution in patients with impaired liver function [51].

Finally, based on the outcome of treatments using IFN and NUCs, the potential markers for the treatment endpoints of CHB patients may be the negativity of HBV DNA, normalization of ALT, and HBsAg negativity with or without seroconversion to anti-HBs [52].

\section{Ongoing and future innovative treatment modalities targeting the virus}

It became evident that commercially available antiviral drugs are endowed with potent antiviral properties and can also contain the pathological processes and development of complications in some patients with CHB. However, as this may not be sufficient, investigators have been trying to target HBV treatment by developing other modes of therapy. One of the notable modes is the development of an HBV-entry inhibitor. Bulevirtide has appeared as an entry inhibitor, which can inactivate HBV receptors and compete with HBV for the sodium-taurocholate co-transporting polypeptide. Thus, it can block the HBV infection in hepatocytes and also accomplish HBV transcriptional suppression [53]. However, data from randomized clinical trials on its utility have yet to emerge. Another area of novel drug development targets hepatitis B transcription from cccDNA. Although this drug has been assessed in cell lines, it may be a prospective new mode of therapy. GLP-26, an HBV capsid assembly modulator (CAM), is a novel glyoxamide derivative that is capable of modulating capsid assembly. The antiviral properties of GLP-26 have been evaluated in a humanized mice model, and the drug has been found to have sustained antiviral properties [54, 55]. Moreover, some drugs that target ribonuclease $\mathrm{H}$ for inducing antiviral effects are in the developmental stage [56]. Another area of drug development for antiviral therapy against HBV may involve using nucleic acid polymers that block the release of subviral particles from hepatocytes. Although it seems to be an effective drug for CHB, its safety and efficacy have not yet been established in CHB patients [57]. When taken together, it is apparent that in addition to commercially available NUCs, several drugs are in the pipeline for the treatment of CHB, with the principle aim of reducing HBV and possibly cccDNA. In addition, several novel therapies are on clinical trials. These include capsid inhibitors, HBsAg inhibitors, and small interfering RNA (siRNAs). Furthermore, a nucleic acid polymer has also been used to reduce HBsAg. Most of these innovative therapies have not been brought to clinics yet. Recently, a nucleic acid polymer has been used in clinical trials in Bangladesh [58, 59].

\section{Lesson learnt from the treatment of CHB patients by IFN, Peg-IFN, and various forms of NUCs}

The unsatisfactory antiviral properties, notable adverse effects, insignificant anti-fibrotic properties, limitation of sustainability of positive activities, and patient's unfriendly attitude toward IFNs and NUCs have revealed that a reduction or negativity of HBV DNA in the blood does not represent the sole target of CHB therapy. The scientific message is a little complex, indicating that there has been a considerable misunderstanding about the development of a drug for CHB patients. Both IFNs and NUCs are not evidence-based drugs for $\mathrm{CHB}$, and these drugs have not been developed by analyzing the pathogenesis of CHB. The antiviral therapy of CHB patients has always reduced HBV DNA or attained HBV DNA negativity. However, CHB represents a complex pathological entity. The hallmark of this virus is its property of not being cytopathic to hepatocytes. HBV also contains no toxin, i.e., it does not directly destroy the cell. Thus, a non-cytopathic virus induces pathogenicity in ways other than regulating virus replication. Asymptomatic infections by HBV have been reported for decades by us as well as other investigators, thus supporting the aforementioned concept. Epidemiological data has also highlighted these observations [60-64]. About two billion of the total 7.6 billion people in the world have been infected by HBV at some point in their life; among them, only approximately 250 million (12.5\%) allow HBV replication as determined by HBV DNA/or HBsAg positivity in the blood. It is of utmost importance to assess how HBV replication and HBsAg production are reasonably controlled in the remaining $87.5 \%$ of HBV-infected subjects. Out of the 250 million chronic 
HBV-infected patients, about $20 \%$ are prone to developing an elevation of ALT (a measure of hepatitis), and some of them progress to develop LC and HCC. The assessment of HBV DNA in the sera has shown that the levels of HBV DNA are not representative of the extent of liver damage; millions of asymptomatic, healthy HBV-infected subjects have shown diverse levels of HBV DNA [65-69]. On the other hand, many patients with progressive liver diseases, such as LC and HCC, have shown low HBV DNA levels [70-72]. These facts, therefore, warranted the development of novel drugs for the containment of CHB and related complications.

\section{HBV-induced inflammation of the liver is immune-mediated}

As HBV is non-cytopathic, several investigators have found that HBV-induced liver damage is immunemediated. If we analyze the immunity of CHB patients, a complex situation is exposed. Patients with CHB harbor HBsAg in their sera, but they usually do not express anti-HBs. On the other hand, patients with CHB may be expressing $\mathrm{HBeAg}$ and anti-HBe. In addition, antibodies to hepatitis B core antigen ( $\mathrm{HBcAg})$ are detected in almost all HBV-infected subjects irrespective of their liver damage [73-79].

From the discovery of HBV until the end of the 20th century (about 25 years), attention to HBV-induced immunity has mainly been focused on the humoral immune responses [80-84] important for prophylaxis from HBV infection.

In time, two important developments regarding the immune responses of CHB, cancers, and other pathologies came about. First, considerable insights were developed into cellular immunity, and second, additional insights were developed into non-antigen-specific versus HBV antigen-specific immunity. The role of cellular immunity in controlling intracellular virus without destroying the cells, regarded as non-cytopathic control of virus, became visible in the HBV infection [85-89]. Moreover, the concept of protective immunity versus pathogenic immunity became evident in the context of CHB [90-93].

\section{Developing the concept of immune therapy for CHB}

IFNs were discovered in 1957 by the British bacteriologist Alick Isaacs and his group [94, 95]. Research conducted in the 1970's revealed that these substances could prevent viral infection and suppress the growth of cancers in some laboratory animals. IFNs got their name because they "interfere" with viruses and keep them from multiplying. In 1986, the first lab-made IFN was created to treat certain types of cancer. One of the first clinical uses of IFN was to treat a rare form of leukemia, known as hairy cell leukemia, which results from the over-production of mature (and abnormal) B-cells [96-99].

NUCs comprise an important class of drugs for the treatment of viral infections. They inhibit DNA/RNA polymerization after being incorporated into nascent DNA/RNA, preventing primer extension. NUCs are nucleosides containing nucleic acid analogue and sugar and/or phosphate groups with one to three phosphates. The first class of drugs that was proved to have clinically significant anti-HIV activity was the nucleoside analog reverse transcriptase inhibitors (NRTIs): zidovudine (AZT), didanosine, zalcitabine, stavudine, lamivudine, and abacavir [listed here in order of their approval by the US Food and Drug Administration (FDA)]. Next, it was recommended for use in CHB patients. Once they are phosphorylated, they work as antimetabolites by being similar enough to nucleotides to be incorporated into growing DNA strands. Nevertheless, they act as chain terminators and stop viral DNA polymerase. They are not specific to viral DNA and also affect mtDNA [100-103].

These historical facts make it clear that anti-HBV drugs have not been developed based on their pathogenicity of chronic HBV infection. Rather, the drugs developed for other pathological conditions have been re-purposed for CHB. However, CHB is a complex pathological condition, and re-purposed drugs may not be suitable for controlling the disease pathogenesis.

\section{Lesson learnt from immune therapy of $\mathrm{CHB}$ by polyclonal immune modulators}

On learning that CHB patients are endowed with impaired or distorted immunity in the context of HBV, attempts were made to upregulate host immunity through polyclonal immune modulators that became the 
first choice of innovative immune therapy. Most of the commercially available agents were initially used to regulate host immunity in CHB patients. These included interleukin (IL)-2, IL-12, granulocyte-macrophage colony-stimulating factor (GM-CSF), levamisole, thymus humoral factor-gamma 2, alpha galactosylceramide, propagermanium, liver extract, thymosin-alpha 1, and some other agents [104-113]. From different articles, it became evident that sufficient amounts of immune modulators could not be used in some cases. The outcomes of these trials were not encouraging. We assume that these therapies were endowed with several inherent limitations, such as the absence of a proper design for the clinical trials and lack of follow-up data. Moreover, there were serious concerns about the safety of these approaches. Tilg et al. [104] reported that even at a toxic dose of IL-2, it could not induce long-term therapeutic benefits in CHB patients. An insignificant response of IL-2 was also reported by Artillo et al. [105]. Woltman et al. [110] did not find any substantial effects of alpha-galactosylceramide in CHB patients. It appears that well-designed clinical trials of phase I/II levels should be conducted to make a realistic assessment of the potentiality and limitation of polyclonal immune modulators in CHB patients. To optimize the design of immune therapy, various approaches were taken by different investigators in animal models of HBV infection. Isogawa et al. [114] showed that TLR signaling inhibits HBV replications in HBV transgenic mice (HBV TM). Initial preclinical studies were accompanied in HBV TM. In line with this, the TLR ligands were developed as drugs for treating CHB. The TLR-7 agonist GS-9620 has been used in patients with CHB. However, administering GS-9620 for twelve weeks had no significant effect on serum hepatitis B surface antigen levels $[115,116]$.

\section{Preclinical studies to optimize antigen-specific immune therapy in HBV TM}

Several lines of HBV TM have been developed in the 1980's to study the cellular and molecular events underlying HBV pathogenesis. As these HBV TM were diverse, variable data was retrieved from the studies of HBV TM to develop insights. The HBV TM that we used was prepared by microinjecting the full genome of HBV plus 619 bp in C57BL/6 mice. HBV TM expressed Dane particle and harbored HBV DNA, HBsAg, and HBeAg [117-120]. Others used different HBV TM lines, and some expressed some antigens with or without HBV DNA in the sera [121]. The administration of polyclonal immune modulators such as concanavalin A, lipopolysaccharides (LPS), and IFN-gamma did not have any antiviral effect regarding HBV DNA reduction or HBsAg levels in HBV TM. Thus, it was concluded that polyclonal immune modulators might not be a good choice for treating HBV infection.

Antigen-specific immune therapy was started in HBV TM by administering HBsAg in complete Freund's adjuvant (CFA). This approach resulted in HBV DNA negativity, HBsAg negativity, and the production of anti-HBs with increased HBsAg-specific T cell proliferation in HBV TM. This study provided the first impetus for using HBsAg-specific immune therapy for CHB patients. We also retrieved mechanisms that clarified why HBV TM did not respond to endogenous HBsAg but expressed vigorous response to HBsAg when administered with CFA. Our study and studies by others revealed that the administration of self-antigens and a danger signal can induce immunity even against the so-called tolerogenic antigens. We also found that the impaired function of antigen-presenting dendritic cells (DC) to process and present antigens to T cells in HBV TM may be responsible for the non-responsiveness to endogenous HBsAg [122-133]. Other laboratories have also provided similar data about antigen-specific immune modulation in HBV TM [134-136].

\section{Vaccine therapy in CHB patients}

It is a common perception that proper antigen-specific immunity protects the host from infectious diseases, and this opened the way for vaccine-induced protection of various hosts from several infectious diseases. The proposals of Paul Ehrlich and William Coley in 1890 may be regarded as the first concept of immune therapy for chronic diseases and cancer. A new field of immune therapy for the treatment of CHB patients was discovered in the mid-1990's. Although HBV has several antigens, HBsAg was used initially as it was commercially available as a prophylactic vaccine. It was, therefore, possible to initiate a therapeutic trial with the HBsAg-based vaccine as a therapeutic vaccine. Pol et al. [137] first used an HBsAg-based vaccine as a therapeutic approach in CHB patients in 1994. They reported that the HBsAg-based vaccine therapy 
induced reduction of HBV DNA, HBeAg seronegative, and anti-HBe seroconversion in some CHB patients. At the same time, several investigators applied various versions of HBsAg-based immune therapy in CHB patients [138-151]. The nature of HBsAg, the dose, and the duration of therapy varied considerably among trials. It was found that HBsAg-based therapeutic vaccine caused reduced HBV replication and some biochemical improvement in some patients. However, these effects were short-lived, resulting in the HBsAg-based vaccine therapy not standing the test of time as a therapeutic vaccine for CHB patients. There were several attempts to improve HBsAg-based vaccines by alerting the design of vaccination, inducing combination therapy and altering the therapeutic vaccine. An antigen-antibody complex vaccine by a Chinese group contained HBsAg and the anti-HBs as a therapeutic vaccine [140]. Strong adjuvants and DNA-based vaccines were used as therapeutic vaccines. Some investigators, including us, loaded antigen-presenting DC with HBsAg to produce HBsAg-pulsed DCs and used them as therapeutic vaccines on CHB patients [148-150]. Some clinical trials inspired optimism about the clinical utility of this vaccine. However, long-term follow-up data was mostly unavailable.

\section{Mechanism of improper therapeutic effect of HBsAg-based therapeutic vaccine for the treatment of $\mathrm{CHB}$ patients}

Some investigators, including us, found that HBsAg-based vaccine therapy may not be an evidence-based approach for treating CHB patients. The main purpose of the HBsAg-based therapeutic vaccine was to emphasize the importance of humoral immune response to $\mathrm{HBsAg}$, which is fundamental to immune prophylaxis of HBV infection. However, to develop a therapeutic vaccine, there is a need to induce cellular immune responses. To gain insights into these events and critical factors, we first checked the immunity of HBV TM, immunized by HBsAg. When it was found that antigen-presenting DC play a cardinal role in this respect, we pulsed HBsAg with antigen-presenting DC that showed that immunity might have been altered in HBV TM. However, the sustained anti-HBV effect was not achieved by using the HBsAg-based cellular approach. In the meantime, Vandepapelière et al. [151] provided credible evidence regarding the insignificant therapeutic efficacy of an HBsAg-based vaccine in CHB patients. They also proposed the utility of HBcAg in therapeutic vaccine development. The observation of Maini et al. [152,153] supported the usage of HBcAg. They showed that the frequencies of HBcAg-specific cytotoxic T lymphocytes (CTLs) were higher in patients with CHB-controlling liver damage and containing HBV DNA replication, compared to CHB patients who were unable to control HBV DNA and liver damages.

\section{Therapeutic vaccine containing both HBsAg and HBcAg in HBV TM}

We assumed that HBsAg and HBcAg would be required to contain HBV DNA and control liver damage in CHB patients. Humoral immunities would be required for neutralizing circulating HBsAg in CHB patients. HBcAg-specific T cells would be required to down-regulate HBV DNA replication in the liver. In line with this concept, a therapeutic vaccine called NASVAC, which contains both HBsAg and HBcAg, was developed by the Center for Genetic Engineering and Biotechnology (CIGB), Havana, Cuba. NASVAC was applied in HBV TM, and persistent HBV DNA negativity along with the production of anti-HBs were recorded in HBV TM [154]. In addition, the administration of NASVAC resulted in cytotoxic T lymphocytes in the liver of HBV TM.

\section{Clinical trials with NASVAC in patients with CHB}

In order to conduct clinical trials with NASVAC, first, the safety and immunogenicity of NASVAC were assessed in normal volunteers [155]. Next, phase I/II clinical trials were accomplished in treatment-naive patients with CHB [156]. NASVAC was developed so that it could be administered via the nasal route and through the parental pathway. Nasal administration was advocated to induce mucosal immunity. In addition, this route of administration seemed to be patient-friendly to people of developing countries. Initially, NASVAC was administered in 18 patients with CHB, 10 times through the nasal route, once in every two weeks. This was followed by five administrations of NASVAC via both nasal and subcutaneous routes. Thus, the entire treatment took four and a half months. In the phase I/II clinical trial with NASVAC, 18 treatment-naive 
patients with CHB received NASVAC 15 times [157]. The vaccine was safe for CHB patients and induced both HBV DNA negativity and normalization of ALT in 50\% of patients. This study also revealed that NASVAC activated DC in an antigen-specific manner [157]. Subsequently, a phase III clinical trial in treatment-naive patients also exposed the antiviral and liver-protecting capacity of NASVAC. A total of 160 patients with HBV DNA in the sera and ALT above the upper limit of normal were enrolled in this phase III clinical trial. Eighty patients received 15 doses of NASVAC as described in the Phase I/II clinical trial. The remaining 80 patients, who were randomly selected, received Peg-IFN once a week for 48 weeks. The follow-up duration was 24 weeks after the end of treatment (EOT). NASVAC confirmed its safety again, and no adverse effects were detected. Moreover, NASVAC was found to be superior to Peg-IFN in containing HBV DNA and normalizing ALT in sera [157]. Recently, we assessed the antifibrotic effect of NASVAC in CHB patients. It was found that NASVAC is endowed with extremely inspiring antifibrotic activity and that it is superior to Peg-IFN (data not shown).

\section{Innovative therapeutic approaches for treating CHB patients}

Here, we have provided a detailed account of the scope and limitations of IFN, Peg-IFN, and NUCs for treating CHB patients. These groups of commercially available drugs form the ongoing background of treating CHB patients. As per the recommendations of American Association for the Study of Liver Diseases (AASLD), European Association for the Study of the Liver (EASL), Asian Pacific Association for the Study of the Liver (APASL), and other regional and national liver organizations, these drugs are the only choice for the treatment of CHB patients.

Furthermore, immune therapy has a three-decade-long history to optimize CHB therapy as an evidence-based and finite therapeutic regimen. This includes treatment with polyclonal immune modulators, HBsAg-based vaccine, epitope-based vaccine, $\mathrm{HBsAg} / \mathrm{HBcAg}$-based vaccine, DNA vaccine, and a combination of vaccine therapy with antivirals drugs. Furthermore, T cell-based therapy and other innovative therapies add to the growing list of treatment approaches for CHB patients [158].

\section{Conclusions}

Infection with HBV presents a highly complex medical and social problem for humanity. This problem is magnified when an individual develops CHB. The impact of HBV and CHB is long-lasting. Even if all normal individuals are vaccinated, public health measures are properly followed, and all prospective candidates get treatment with existing and recommended drugs, we will have to live with HBV for a century or more. The viral life cycle teaches us that HBV is not an eradicable virus, and thus, the world body has entered a phase of "Elimination of Hepatitis by 2030". Even with a vaccine coverage of more than $80 \%$ among children and adherence to public health measures, the world is experiencing approximately 30 million new HBV infections per year. Moreover, with the presence of several antiviral drugs, approximately 0.8 million people die of HBV-related complications. Thus, innovative concepts are urgently needed to fight against HBV-related conditions, and these should be implemented through comprehensive approaches by developing and developed countries. The most practical approach may be a combination therapy in which both antiviral drugs and immune modulators can accomplish their respective functions to tackle the virus as well as liver damage in CHB patients.

\section{Abbreviations}

ALT: alanine aminotransferase

anti-HBe: antibody to HBeAg

anti-HBs: antibody to HBsAg

cccDNA: close covalently circular DNA

CHB: chronic hepatitis B

DC: dendritic cells 
HBcAg: hepatitis B core antigen

HBeAg: hepatitis B e antigen

HBsAg: hepatitis B surface antigen

HBV: hepatitis B virus

HBV TM: hepatitis B virus transgenic mice

HCC: hepatocellular carcinoma

IFN: interferon

IL: interleukin

LC: cirrhosis of liver

NUCs: nucleoside analogs

Peg-IFN: pegylated interferon

TLR: toll-like receptors

\section{Declarations}

\section{Author contributions}

SMFA planned the study and contributed in data compilation and analysis. MM accomplished as principal investigator of the trial. JCA, and MHU, contributed conception and design of the study; MSIK analyzed the data and compiled the statistical analysis. EP, and GNG performed the analytical works. OY analyzed data. YH had overall supervision. All authors contributed to manuscript revision, read and approved the submitted version.

\section{Conflicts of interest}

The authors declare that they have no conflicts of interest.

\section{Ethical approval}

Not applicable.

\section{Consent to participate}

Not applicable.

Consent to publication

Not applicable.

\section{Availability of data and materials}

Not applicable.

\section{Funding}

The study was supported in part by a grant-in-aid from the Japan Agency for Medical Research and Development (AMED) to Sheikh Mohammad Fazle Akbar (Grant number 20fk0310103h1904). The funders had no role in study design, data collection and analysis, decision to publish, or preparation of the manuscript.

\section{Copyright}

(C) The Author(s) 2021.

\section{References}

1. Mühlemann B, Jones TC, Damgaard PB, Allentoft ME, Shevnina I, Logvin A, et al. Ancient hepatitis B viruses from the Bronze Age to the Medieval period. Nature. 2018;557:418-23.

2. Polaris Observatory Collaborators. Global prevalence, treatment, and prevention of hepatitis B virus infection in 2016: a modelling study. Lancet Gastroenterol Hepatol. 2018;3:383-403. 
3. Hepatitis B facts and figures [Internet]. Doylestown: Hepatitis B foundation. c2021 [cited 2021 Sep 23]. Available from: https://www.hepb.org/what-is-hepatitis-b/what-is-hepb/facts-and-figures/\#: :text= Two\%20billion\%20people\%20have\%20been,million\%20people\%20are\%20chronically\%20infected

4. Papatheodoridis GV, Manolakopoulos S, Dusheiko G, Archimandritis AJ. Therapeutic strategies in the management of patients with chronic hepatitis B virus infection. Lancet Infect Dis. 2008;8:167-78.

5. Ozaras R, Khodor H, Yetim N, Unal UK, Demirhan YE, Gultekin G, et al. Monotherapy for hepatitis B infection: a review of treatment options. Expert Rev Anti Infect Ther. 2015;13:1457-68.

6. Bourlière M, Rabiega P, Ganne-Carrie N, Serfaty L, Marcellin P, Barthe Y, et al. Effect on HBs antigen clearance of addition of pegylated interferon alfa-2a to nucleos $(t)$ ide analogue therapy versus nucleos $(\mathrm{t})$ ide analogue therapy alone in patients with HBe antigen-negative chronic hepatitis B and sustained undetectable plasma hepatitis B virus DNA: a randomised, controlled, open-label trial. Lancet Gastroenterol Hepatol. 2017;2:177-88.

7. Martinez MG, Testoni B, Zoulim F. Biological basis for functional cure of chronic hepatitis B. J Viral Hepat. 2019;26:786-94.

8. Gill US, Kennedy PTF. The impact of currently licensed therapies on viral and immune responses in chronic hepatitis B: considerations for future novel therapeutics. J Viral Hepat. 2019;26:4-15.

9. Viganò M, Grossi G, Loglio A, Lampertico P. Treatment of hepatitis B: is there still a role for interferon? Liver Int. 2018;38 Suppl 1:79-83.

10. Akbar SM, Hiasa Y, Mishiro S, Onji M. Treatment of hepatitis B virus-infected patients: utility of therapeutic recommendations in developing countries. Expert Opin Pharmacother. 2009;10:1605-14.

11. Belloni L, Allweiss L, Guerrieri F, Pediconi N, Volz T, Pollicino T, et al. IFN- $\alpha$ inhibits HBV transcription and replication in cell culture and in humanized mice by targeting the epigenetic regulation of the nuclear cccDNA minichromosome. J Clin Invest. 2012;122:529-37.

12. Yuan Y, Yuan H, Yang G, Yun H, Zhao M, Liu Z, et al. IFN- $\alpha$ confers epigenetic regulation of HBV cccDNA minichromosome by modulating GCN5-mediated succinylation of histone H3K79 to clear HBV cccDNA. Clin Epigenet. 2020;12:135.

13. Stadler D, Kächele M, Jones AN, Hess J, Urban C, Schneider J, et al. Interferon-induced degradation of the persistent hepatitis B virus cccDNA form depends on ISG20. EMBO Rep. 2021;22:e49568.

14. Ding $S$ and Robek MD. Cytidine deamination and cccDNA degradation: a new approach for curing HBV? Hepatology. 2014;60:2118-21.

15. Liu F, Campagna M, Qi Y, Zhao X, Guo F, Xu C, et al. Alpha-interferon suppresses hepadnavirus transcription by altering epigenetic modification of cccDNA minichromosomes. PLoS Pathog. 2013;9:e1003613.

16. Inagaki $Y$, Nemoto $T$, Kushida $M$, Sheng $Y$, Higashi $K$, Ikeda $K$, et al. Interferon alfa down-regulates collagen gene transcription and suppresses experimental hepatic fibrosis in mice. Hepatology. 2003;38:890-9.

17. Micco L, Peppa D, Loggi E, Schurich A, Jefferson L, Cursaro C, et al. Differential boosting of innate and adaptive antiviral responses during pegylated-interferon-alpha therapy of chronic hepatitis B. J Hepatol. 2013;58:225-33.

18. Dusheiko G. Treatment of HBeAg positive chronic hepatitis B: interferon or nucleoside analogues. Liver Int. 2013;33 Suppl 1:137-50.

19. Wang G, Guan J, Khan NU, Li G, Shao J, Zhou Q et al. Potential capacity of interferon- $\alpha$ to eliminate covalently closed circular DNA (cccDNA) in hepatocytes infected with hepatitis B virus. Gut Pathog. 2021;13:22.

20. Zoulim F, Durantel D. Antiviral therapies and prospects for a cure of chronic hepatitis B. Cold Spring Harb Perspect Med. 2015;5:a021501.

21. Kawashima K, Isogawa M, Hamada-Tsutsumi S, Baudi I, Saito S, Nakajima A, et al. Type I Interferon interferon signaling prevents hepatitis B virus-specific $\mathrm{T}$ cell responses by reducing antigen expression. J Virol. 2018;92:e01099-18. 
22. Christen V, Duong F, Bernsmeier C, Sun D, Nassal M, Heim MH. Inhibition of alpha interferon signaling by hepatitis B virus. J Virol. 2007;81:159-65.

23. Perrillo R. Benefits and risks of interferon therapy for hepatitis B. Hepatology. 2009;49:S103-11.

24. Wiegand J, van Bömmel F, Berg T. Management of chronic hepatitis B: status and challenges beyond treatment guidelines. Semin Liver Dis. 2010;30:361-77.

25. Xu XW, Chen YG. Current therapy with nucleoside/nucleotide analogs for patients with chronic hepatitis B. Hepatobiliary Pancreat Dis Int. 2006;5:350-9.

26. Lin CL, Kao JH. Recent advances in the treatment of chronic hepatitis B. Expert Opin Pharmacother. 2011;12:2025-40.

27. Hadziyannis SJ. Milestones and perspectives in viral hepatitis B. Liver Int. 2011;31 Suppl 1:129-34.

28. Li T, Liang Y, Zhang M, Liu F, Zhang L, Yang B, et al. Nucleoside/nucleotide analog consolidation therapy in hepatitis B e-antigen positive chronic hepatitis B patients: three years should be preferred. Hepatol Res. 2021;51:633-40.

29. Gan W, Li J, Zhang C, Chen X, Lin C, Gao Z. Efficacy of 104-week Telbivudine-based optimization strategy in patients with HBeAg-negative chronic hepatitis B virus infections. BMC Infect Dis. 2020;20:931.

30. Charlton MR, Alam A, Shukla A, Dashtseren B, Lesmana CRA, Duger D, et al. An expert review on the use of tenofovir alafenamide for the treatment of chronic hepatitis B virus infection in Asia. J Gastroenterol. 2020;55:811-23.

31. Köklü S, Tuna Y, Gülșen MT, Demir M, Köksal AŞ, Koçkar MC, et al. Long-term efficacy and safety of lamivudine, entecavir, and tenofovir for treatment of hepatitis B virus-related cirrhosis. Clin Gastroenterol Hepatol. 2013;11:88-94.

32. Woo G, Tomlinson G, Nishikawa Y, Kowgier M, Sherman M, Wong DK, et al. Tenofovir and entecavir are the most effective antiviral agents for chronic hepatitis B: a systematic review and Bayesian meta-analyses. Gastroenterology. 2010;139:1218-29.

33. Chen YC, Jeng WJ, Hsu CW, Lin CY. Impact of hepatic steatosis on treatment response in nuclesos(t) ide analogue-treated HBeAg-positive chronic hepatitis B: a retrospective study. BMC Gastroenterol. 2020;20:146.

34. Papatheodoridis GV, Idilman R, Dalekos GN, Buti M, Chi H, van Boemmel F, et al. The risk of hepatocellular carcinoma decreases after the first 5 years of entecavir or tenofovir in Caucasians with chronic hepatitis B. Hepatology. 2017;66:1444-53.

35. Wong D, Littlejohn M, Edwards R, Jackson K, Revill P, Gaggar A, et al. ALT flares during nucleotide analogue therapy are associated with HBsAg loss in genotype A HBeAg-positive chronic hepatitis B. Liver Int. 2018;38:1760-9.

36. Wilt TJ, Shamliyan T, Shaukat A, Taylor BC, MacDonald R, Yuan JM, et al. Management of chronic hepatitis B. Evid Rep Technol Assess (Full Rep). 2008;174:1-671.

37. Shamliyan TA, MacDonald R, Shaukat A, Taylor BC, Yuan JM, Johnson JR, et al. Antiviral therapy for adults with chronic hepatitis B: a systematic review for a National Institutes of Health Consensus Development Conference. Ann Intern Med. 2009;150:111-24.

38. Shamliyan TA, Johnson JR, MacDonald R, Shaukat A, Yuan JM, Kane RL, et al. Systematic review of the literature on comparative effectiveness of antiviral treatments for chronic hepatitis B infection. J Gen Intern Med. 2011;26:326-39.

39. Liaw YF. Natural history of chronic hepatitis B virus infection and long-term outcome under treatment. Liver Int. 2009;29 Suppl 1:100-7.

40. Liu S, Liu Z, Li W, Zhou B, Liang X, Fan R, et al. Factors associated with the biphasic kinetics of serum HBV RNA in patients with HBeAg-positive chronic hepatitis B treated with nucleos(t)ide analogues. Aliment Pharmacol Ther. 2020;52:692-700. 
41. Liem KS, Fung S, Wong DK, Yim C, Noureldin S, Chen J, et al. Limited sustained response after stopping nucleos(t)ide analogues in patients with chronic hepatitis B: results from a randomised controlled trial (Toronto STOP study). Gut. 2019;68:2206-13.

42. Bzowej NH, Tran TT, Li R, Belle SH, Smith CI, Khalili M, et al; Hepatitis B Research Network (HBRN). Total alanine aminotransferase (ALT) flares in pregnant North American women with chronic hepatitis B infection: results from a prospective observational study. Am J Gastroenterol. 2019;114:1283-91.

43. Koukoulioti E, Brodzinski A, Mihm U, Sarrazin C, Jung MC, Schott E, et al. Risk factors for resistance development against lamivudine during long-term treatment of chronic hepatitis B virus infections. Eur J Gastroenterol Hepatol. 2019;31:845-52.

44. Feld JJ, Terrault NA, Lin HS, Belle SH, Chung RT, Tsai N, et al; Hepatitis B Research Network. Entecavir and peginterferon alfa-2a in adults with hepatitis B e antigen-positive immune-tolerant chronic hepatitis B virus infection. Hepatology. 2019;69:2338-48.

45. Rodríguez M, Pascasio JM, Fraga E, Fuentes J, Prieto M, Sánchez-Antolín G, et al; TENOSIMP-B Research Group. Tenofovir vs. lamivudine plus adefovir in chronic hepatitis B: TENOSIMP-B study. World J Gastroenterol. 2017;23:7459-69.

46. Omata M, Kanda T, Wei L, Yu ML, Chuang WL, Ibrahim A, et al. APASL consensus statements and recommendations for hepatitis $C$ prevention, epidemiology, and laboratory testing. Hepatol Int. 2016;10:681-701.

47. Terrault NA, Lok ASF, McMahon BJ, Chang KM, Hwang JP, Jonas MM, et al. Update on prevention, diagnosis, and treatment of chronic hepatitis B: AASLD 2018 hepatitis B guidance. Hepatology. 2018;67:1560-99.

48. Chen TM, Chang CC, Huang PT, Wen CF, Lin CC. Performance of risk estimation for hepatocellular carcinoma in chronic hepatitis B (REACH-B) score in classifying treatment eligibility under 2012 Asian Pacific Association for the Study of the Liver (APASL) guideline for chronic hepatitis B patients. Aliment Pharmacol Ther. 2013;37:243-51.

49. European Association for the Study of the Liver. EASL 2017 clinical practice guidelines on the management of hepatitis B virus infection. 2017;67:370-98.

50. Lin CL, Kao JH. Review article: novel therapies for hepatitis B virus cure - advances and perspectives. Aliment Pharmacol Ther. 2016;44:213-22.

51. Khungar V, Han SH. A systematic review of side effects of nucleoside and nucleotide drugs used for treatment of chronic hepatitis B. Curr Hepat Rep. 2010;9:75-90.

52. Cornberg M, Lok AS, Terrault NA, Zoulim F; 2019 EASL-AASLD HBV Treatment Endpoints Conference Faculty. Guidance for design and endpoints of clinical trials in chronic hepatitis B - report from the 2019 EASL-AASLD HBV Treatment Endpoints Conference. J Hepatol. 2020;72:539-57.

53. Cheng D, Han B, Zhang W, Wu W. Clinical effects of NTCP-inhibitor myrcludex B. J Viral Hepat. 2021;28:852-8.

54. Nkongolo S, Nußbaum L, Lempp FA, Wodrich H, Urban S, Ni Y. The retinoic acid receptor (RAR) $\alpha$-specific agonist Am80 (tamibarotene) and other RAR agonists potently inhibit hepatitis B virus transcription from cccDNA. Antiviral Res. 2019;168:146-55.

55. Roca Suarez AA, Testoni B, Zoulim F. HBV 2021: new therapeutic strategies against an old foe. Liver Int. 2021;41 Suppl 1:15-23.

56. Amblard F, Boucle S, Bassit L, Cox B, Sari O, Tao S, et al. Novel hepatitis B virus capsid assembly modulator induces potent antiviral responses in vitro and in humanized mice. Antimicrob Agents Chemother. 2020;64:e01701-19.

57. Tavis JE, Zoidis G, Meyers MJ, Murelli RP. Chemical approaches to inhibiting the hepatitis B virus ribonuclease H. ACS Infect Dis. 2019;5:655-8.

58. Alexopoulou A, Vasilieva L, Karayiannis P. New approaches to the treatment of chronic hepatitis B. J Clin Med. 2020;9:3187. 
59. Al-Mahtab M, Bazinet M, Vaillant A. Safety and efficacy of nucleic acid polymers in monotherapy and combined with immunotherapy in treatment-naive Bangladeshi patients with HBeAg+ chronic hepatitis B infection. PLoS One. 2016;11:e0156667.

60. Iloeje UH, Yang HI, Chen CJ. Natural history of chronic hepatitis B: what exactly has REVEAL revealed? Liver Int. 2012;32:1333-41.

61. Chisari FV, Isogawa M, Wieland SF. Pathogenesis of hepatitis B virus infection. Pathol Biol (Paris). 2010;58:258-66.

62. Cassidy A, Mossman S, Olivieri A, De Ridder M, Leuroux-Roels G. Hepatitis B vaccine effectiveness in the face of global HBV genotype diversity. Expert Rev Vaccines. 2011;10:1709-15.

63. Hilleman MR. Overview of the pathogenesis, prophylaxis, and therapeusis of viral hepatitis $B$, with focus on reduction to practical applications. Vaccine. 2001;19:1837-48.

64. Wu JF, Chang MH. Natural history of chronic hepatitis B virus infection from infancy to adult life - the mechanism of inflammation triggering and long-term impacts. J Biomed Sci. 2015;22:92.

65. Al-Mahtab M, Rahman S, Akbar SM, Kamal M, Khan MS. Clinical use of liver biopsy for the diagnosis and management of inactive and asymptomatic hepatitis B virus carriers in Bangladesh. J Med Virol. 2010;82:1350-4.

66. Al-Mahtab M, Akbar SM, Rahman S, Kamal M, Khan MS. Biochemical, virological, immunological and histopathological features of 702 incidentally detected chronic hepatitis B virus carriers in Bangladesh. Digestion. 2012;86:1-5.

67. Kumar M, Chauhan R, Gupta N, Hissar S, Sakhuja P, Sarin SK. Spontaneous increases in alanine aminotransferase levels in asymptomatic chronic hepatitis B virus-infected patients. Gastroenterology. 2009;136:1272-80.

68. Han W, Ni Q, Liu K, Yao Y, Zhao D, Liu X, et al. Decreased CD122 on CD56dim NK associated with its impairment in asymptomatic chronic HBV carriers with high levels of HBV DNA, HBsAg and HBeAg. Life Sci. 2018;195:53-60.

69. Chen $\mathrm{CH}$, Lee CM, Wang JH, Tung HD, Hung CH, Lu SN. Correlation of quantitative assay of hepatitis B surface antigen and HBV DNA levels in asymptomatic hepatitis B virus carriers. Eur J Gastroenterol Hepatol. 2004;16:1213-8.

70. Liu C, Wang L, Xie H, Zhang L, Wang B, Luo C, et al. The relationship between serum hepatitis B virus DNA level and liver histology in patients with chronic HBV infection. PLoS One. 2018;13:e0206060.

71. Kim TS, Sinn DH, Kang W, Gwak GY, Paik YH, Choi MS, et al. Hepatitis B virus DNA levels and overall survival in hepatitis B-related hepatocellular carcinoma patients with low-level viremia. J Gastroenterol Hepatol. 2019;34:2028-35.

72. Kim JH, Sinn DH, Kang W, Gwak GY, Paik YH, Choi MS, et al. Low-level viremia and the increased risk of hepatocellular carcinoma in patients receiving entecavir treatment. Hepatology. 2017;66:335-43.

73. Lin MH, Li HQ, Zhu L, Su HY, Peng LS, Wang CY, et al. Liver fibrosis in the natural course of chronic hepatitis B viral infection: a systematic review with meta-analysis. Dig Dis Sci. 2021;[Epub ahead of print].

74. Suslov A, Meier MA, Ketterer S, Wang X, Wieland S, Heim MH. Transition to HBeAg-negative chronic hepatitis B virus infection is associated with reduced cccDNA transcriptional activity. J Hepatol. 2021;74:794-800.

75. Ghany MG, Feld JJ, Chang KM, Chan HLY, Lok ASF, Visvanathan K, et al. Serum alanine aminotransferase flares in chronic hepatitis B infection: the good and the bad. Lancet Gastroenterol Hepatol. 2020;5: 406-17.

76. Lee HW, Chan HL. Unresolved issues of immune tolerance in chronic hepatitis B. J Gastroenterol. 2020;55:383-9.

77. Mak LY, Seto WK, Fung J, Yuen MF. Use of HBsAg quantification in the natural history and treatment of chronic hepatitis B. Hepatol Int. 2020;14:35-46. 
78. Liaw YF. Clinical utility of HBV surface antigen quantification in HBV e antigen-negative chronic HBV infection. Nat Rev Gastroenterol Hepatol. 2019;16:631-41.

79. Chen HS, Wu JF, Su TH, Chen HL, Hsu HY, Xia NS, et al. Baseline level of hepatitis B core antibody predicts spontaneous hepatitis B e antigen (HBeAg) seroconversion in HBeAg-positive children with a normal alanine aminotransferase level. Hepatology. 2019;70:1903-12.

80. Conrad ME, Knodell RG, Bradley EL Jr, Flannery EP, Ginsberg AL. Risk factors in transmission of non-A, non-B posttransfusion hepatitis. The role of hepatitis B antibody in donor blood. Transfusion. 1977;17:579-85.

81. Budkowska A, Dubreuil P, Capel F, Pillot J. Hepatitis B virus pre-S gene-encoded antigenic specificity and anti-pre-S antibody: relationship between anti-pre-S response and recovery. Hepatology. 1986;6:360-8.

82. Theilmann L, Klinkert MQ Gmelin K, Kommerell B, Pfaff E. Detection of antibodies against pre-S1 proteins in sera of patients with hepatitis B virus (HBV) infection. J Hepatol. 1987;4:22-8.

83. Tanaka Y, Esumi M, Shikata T. Persistence of hepatitis B virus DNA after serological clearance of hepatitis B virus. Liver. 1990;10:6-10.

84. Ferrari C. HBV and the immune response. Liver Int. 2015;35 Suppl 1:121-8.

85. Chen Y, Tian Z. HBV-induced immune imbalance in the development of HCC. Front Immunol. 2019; 10:2048.

86. Maini MK, Pallett LJ. Defective T-cell immunity in hepatitis B virus infection: why therapeutic vaccination needs a helping hand. Lancet Gastroenterol Hepatol. 2018;3:192-202.

87. Eddleston AL, Mondelli M. Immunopathological mechanisms of liver cell injury in chronic hepatitis B virus infection. J Hepatol. 1986;3 Suppl 2:S17-23.

88. Guidotti LG, Chisari FV. Immunobiology and pathogenesis of viral hepatitis. Annu Rev Pathol. 2006; 1:23-61.

89. Wijaya RS, Read SA, Truong NR, Han S, Chen D, Shahidipour H, et al. HBV vaccination and HBV infection induces HBV-specific natural killer cell memory. Gut. 2021;70:357-69.

90. Ma Z, Zhang E, Gao S, Xiong Y, Lu M. Toward a functional cure for hepatitis B: the rationale and challenges for therapeutic targeting of the B cell immune response. Front Immunol. 2019;10:2308.

91. Wang WT, Zhao XQ, Li GP, Chen YZ, Wang L, Han MF, et al. Immune response pattern varies with the natural history of chronic hepatitis B. World J Gastroenterol. 2019;25:1950-63.

92. Chuai X, Xie B, Deng Y, Zhao Y, Wang W, Gao Z, et al. HBV antigen and DNA loss from mouse serum is associated with novel vaccine-induced HBV surface antigen-specific cell-mediated immunity and cytokine production. Antiviral Res. 2019;161:20-7.

93. Dembek C, Protzer U, Roggendorf M. Overcoming immune tolerance in chronic hepatitis B by therapeutic vaccination. Curr Opin Virol. 2018;30:58-67.

94. Isaacs A, Lindenmann J. Virus interference. I. The interferon. Proc R Soc Lond B. 1957;147:258-67.

95. Isaacs A, Burke DC. Viral interference and interferon. Br Med Bull. 1959;15:185-8.

96. Assanto GM, Riemma C, Malaspina F, Perrone S, De Luca ML, Pucciarini A, et al. The current role of interferon in hairy cell leukaemia: clinical and molecular aspects. Br J Haematol. 2021;164:78-82.

97. Ramos Perez J, Ravandi-Kashani F. The pharmacological management of hairy cell leukemia. Expert Opin Pharmacother. 2020;21:1337-44.

98. Silva WFD Junior, Teixeira LLC, Rocha V, Buccheri V. Current role of interferon in hairy cell leukemia therapy: a timely decision. Hematol Transfus Cell Ther. 2019;41:88-90.

99. Mildvan D, Bergé P, Starrett S, St Clair M, Salgo M. Prophylactic zalcitabine and interferon-alpha for a large-bore needlestick exposure to human immunodeficiency virus. J Acquir Immune Defic Syndr (1988). 1994;7:416-7. 
100. Caliendo AM, Hirsch MS. Combination therapy for infection due to human immunodeficiency virus type 1. Clin Infect Dis. 1994;18:516-24.

101. Wilde MI, Langtry HD. Zidovudine. An update of its pharmacodynamic and pharmacokinetic properties, and therapeutic efficacy. Drugs. 1993;46:515-78.

102. Kamali F. Clinical pharmacology of zidovudine and other 2',3'-dideoxynucleoside analogues. Clin Investig. 1993;71:392-405.

103. Mitsuya H, Yarchoan R, Kageyama S, Broder S. Targeted therapy of human immunodeficiency virusrelated disease. FASEB J. 1991;5:2369-81.

104. Tilg H, Vogel W, Tratkiewicz J, Aulitzky WE, Herold M, Gruber M, et al. Pilot study of natural human interleukin-2 in patients with chronic hepatitis B. Immunomodulatory and antiviral effects. J Hepatol. 1993;19:259-67.

105. Artillo S, Pastore G, Alberti A, Milella M, Santantonio T, Fattovich G, et al. Double-blind, randomized controlled trial of interleukin-2 treatment of chronic hepatitis B. J Med Virol. 1998;54:167-72.

106. Carreño V, Zeuzem S, Hopf U, Marcellin P, Cooksley WG, Fevery J, et al. A phase I/II study of recombinant human interleukin-12 in patients with chronic hepatitis B. J Hepatol. 2000;32:317-24.

107. Martín J, Quiroga JA, Bosch O, Carreño V. Changes in cytokine production during therapy with granulocyte-macrophage colony-stimulating factor in patients with chronic hepatitis B. Hepatology. 1994;20:1156-61.

108. Ruiz-Moreno M, García R, Rua MJ, Serrano B, Moraleda G, Feijoo E, et al. Levamisole and interferon in children with chronic hepatitis B. Hepatology. 1993;18:264-9.

109. Farhat BA, Marinos G, Daniels HM, Naoumov NV, Williams R. Evaluation of efficacy and safety of thymus humoral factor-gamma 2 in the management of chronic hepatitis B. J Hepatol. 1995;23:21-7.

110. Woltman AM, Ter Borg MJ, Binda RS, Sprengers D, von Blomberg BM, Scheper RJ, et al. Alphagalactosylceramide in chronic hepatitis B infection: results from a randomized placebo-controlled Phase I/II trial. Antivir Ther. 2009;14:809-18.

111. Hirayama C, Suzuki H, Ito M, Okumura M, Oda T. Propagermanium: a nonspecific immune modulator for chronic hepatitis B. J Gastroenterol. 2003;38:525-32.

112. Israeli E, Safadi R, Melhem A, Pappo O, Shibolet O, Klein A, et al. Induction of oral immune regulation towards liver-extracted proteins for treatment of chronic HBV and HCV hepatitis: results of a phase I clinical trial. Liver Int. 2004;24:295-307.

113. Iino S, Toyota J, Kumada H, Kiyosawa K, Kakumu S, Sata M, et al. The efficacy and safety of thymosin alpha-1 in Japanese patients with chronic hepatitis B; results from a randomized clinical trial. J Viral Hepat. 2005;12:300-6.

114. Isogawa M, Robek MD, Furuichi Y, Chisari FV. Toll-like receptor signaling inhibits hepatitis B virus replication in vivo. J Virol. 2005;79:7269-72.

115. Zhang X, Kraft A, Broering R, Schlaak JF, Dittmer U, Lu M. Preclinical development of TLR ligands as drugs for the treatment of chronic viral infections. Expert Opin Drug Discov. 2012;7:597-611.

116. Boni C, Vecchi A, Rossi M, Laccabue D, Giuberti T, Alfieri A, et al. TLR7 agonist increases responses of hepatitis B virus-specific $T$ cells and natural killer cells in patients with chronic hepatitis B treated with nucleos(t)ide analogues. Gastroenterology. 2018;154:1764-77.e7.

117. Iannacone M, Guidotti LG. Immunobiology and pathogenesis of hepatititis B virus infection. Nat Rev Immunol. 2021;[Epub ahead of print].

118. Araki K, Miyazaki J, Hino 0, Tomita N, Chisaka O, Matsubara K, et al. Expression and replication of hepatitis B virus genome in transgenic mice. Proc Natl Acad Sci U S A. 1989;86:207-11.

119. Yamamura K, Araki K, Hino O, Tomita N, Miyazaki J, Matsubara K. HBV production in transgenic mice. Gastroenterol Jpn. 1990;25 Suppl 2:49-52. 
120. Akbar SK, Onji M. Hepatitis B virus (HBV)-transgenic mice as an investigative tool to study immunopathology during HBV infection. Int J Exp Pathol. 1998;79:279-91.

121. Chisari FV, Pinkert CA, Milich DR, Filippi P, McLachlan A, Palmiter RD, et al. A transgenic mouse model of the chronic hepatitis B surface antigen carrier state. Science. 1985;230:1157-60.

122. Akbar SM, Kajino K, Tanimoto K, Kurose K, Masumoto T, Michitaka K, et al. Placebo-controlled trial of vaccination with hepatitis B virus surface antigen in hepatitis B virus transgenic mice. J Hepatol. 1997;26:131-7.

123. Akbar SM, Yoshida O, Chen S, Cesar AJ, Abe M, Matsuura B, et al. Immune modulator and antiviral potential of dendritic cells pulsed with both hepatitis B surface antigen and core antigen for treating chronic HBV infection. Antivir Ther. 2010;15:887-95.

124. Furukawa S, Akbar SM, Hasebe A, Horiike N, Onji M. Production of hepatitis B surface antigen-pulsed dendritic cells from immunosuppressed murine hepatitis B virus carrier: evaluation of immunogenicity of antigen-pulsed dendritic cells in vivo. Immunobiology. 2004;209:551-7.

125. Furukawa S, Akbar SM, Hasebe A, Horiike N, Onji M. Induction and maintenance of anti-HBs in immunosuppressed murine hepatitis B virus carriers by a novel vaccination approach: implications for use in hepatitis B virus-infected subjects with liver transplantation. J Gastroenterol. 2004;39:851-8.

126. Hasebe A, Akbar SM, Furukawa S, Horiike N, Onji M. Impaired functional capacities of liver dendritic cells from murine hepatitis B virus carrier : Relevance to low HBV-specific immune responses. Clin Exp Immunol. 2005;139:35-42.

127. Chen S, Akbar SM, Abe M, Hiasa Y, Onji M. Immunosuppressive functions of hepatic myeloid-derived suppressor cells of normal mice and in a murine model of chronic hepatitis B virus. Clin Exp Immunol. 2011;166:134-42.

128. Oka Y, Akbar SM, Horiike N, Joko K, Onji M. Mechanism and therapeutic potential of DNA-based immunization against the envelope proteins of hepatitis $\mathrm{B}$ virus in normal and transgenic mice. Immunology. 2001;103:90-7.

129. Akbar SM, Yamamoto K, Abe M, Ninomiya T, Tanimoto K, Masumoto T, et al. Potent synergistic effect of sho-saiko-to, a herbal medicine, during vaccine therapy in a murine model of hepatitis $\mathrm{B}$ virus carrier. Eur J Clin Invest. 1999;29:786-92.

130. Akbar SM, Abe M, Masumoto T, Horiike N, Onji M. Mechanism of action of vaccine therapy in murine hepatitis B virus carriers: vaccine-induced activation of antigen presenting dendritic cells. J Hepatol. 1999;30:755-64.

131. Kurose K, Akbar SM, Yamamoto K, Onji M. Production of antibody to hepatitis B surface antigen (antiHBs) by murine hepatitis B virus carriers: neonatal tolerance versus antigen presentation by dendritic cells. Immunology. 1997;92:494-500.

132. Akbar SM, Inaba K, Onji M. Upregulation of MHC class II antigen on dendritic cells from hepatitis B virus transgenic mice by interferon-gamma: abrogation of immune response defect to a T-cell-dependent antigen. Immunology. 1996;87:519-27.

133. Akbar SM, Onji M, Inaba K, Yamamura K, Ohta Y. Low responsiveness of hepatitis B virus-transgenic mice in antibody response to T-cell-dependent antigen: defect in antigen-presenting activity of dendritic cells. Immunology. 1993;78:468-75.

134. Kimura K, Kakimi K, Wieland S, Guidotti LG, Chisari FV. Activated intrahepatic antigen-presenting cells inhibit hepatitis B virus replication in the liver of transgenic mice. J Immunol. 2002;169:5188-95.

135. Shimizu Y, Guidotti LG, Fowler P, Chisari FV. Dendritic cell immunization breaks cytotoxic T lymphocyte tolerance in hepatitis B virus transgenic mice. J Immunol. 1998;161:4520-9.

136. Mishra D, Mishra PK, Dubey V, Dabadghao S, Jain NK. Evaluation of uptake and generation of immune response by murine dendritic cells pulsed with hepatitis B surface antigen-loaded elastic liposomes. Vaccine. 2007;25:6939-44. 
137. Pol S, Driss F, Michel ML, Nalpas B, Berthelot P, Brechot C. Specific vaccine therapy in chronic hepatitis B infection. Lancet. 1994;344:342.

138. Senturk H, Tabak F, Akdogan M, Erdem L, Mert A, Ozaras R, et al. Therapeutic vaccination in chronic hepatitis B. J Gastroenterol Hepatol. 2002;17:72-6.

139. Wang XY, Zhang XX, Yao X, Jiang JH, Xie YH, Yuan ZH, et al. Serum HBeAg sero-conversion correlated with decrease of HBsAg and HBV DNA in chronic hepatitis B patients treated with a therapeutic vaccine. Vaccine. 2010;28:8169-74.

140. Wen YM, Wu XH, Hu DC, Zhang QP, Guo SQ. Hepatitis B vaccine and anti-HBs complex as approach for vaccine therapy. Lancet. 1995;345:1575-6.

141. Xu DZ, Zhao K, Guo LM, Li LJ, Xie Q, Ren H, et al. A randomized controlled phase IIb trial of antigen-antibody immunogenic complex therapeutic vaccine in chronic hepatitis B patients. PLoS One. 2008;3:e2565.

142. Dahmen A, Herzog-Hauff S, Böcher WO, Galle PR, Löhr HF. Clinical and immunological efficacy of intradermal vaccine plus lamivudine with or without interleukin-2 in patients with chronic hepatitis B. J Med Virol. 2002;66:452-60.

143. Horiike N, Fazle Akbar SM, Michitaka K, Joukou K, Yamamoto K, Kojima N, et al. In vivo immunization by vaccine therapy following virus suppression by lamivudine: a novel approach for treating patients with chronic hepatitis B. J Clin Virol. 2005;32:156-61.

144. Helvaci M, Kizilgunesler A, Kasirga E, Ozbal E, Kuzu M, Sozen G. Efficacy of hepatitis B vaccination and interferon-alpha-2b combination therapy versus interferon-alpha-2b monotherapy in children with chronic hepatitis B. J Gastroenterol Hepatol. 2004;19:785-91.

145. Hoa PT, Huy NT, Thu le T, Nga CN, Nakao K, Eguchi K, et al. Randomized controlled study investigating viral suppression and serological response following pre-S1/pre-S2/S vaccine therapy combined with lamivudine treatment in HBeAg-positive patients with chronic hepatitis B. Antimicrob Agents Chemother. 2009;53:5134-40.

146. Traquina P, Morandi M, Contorni M, Van Nest G. MF59 adjuvant enhances the antibody response to recombinant hepatitis B surface antigen vaccine in primates. J Infect Dis. 1996;174:1168-75.

147. Yang FQ, Yu YY, Wang GQ Chen J, Li JH, Li YQ et al. A pilot randomized controlled trial of dual-plasmid HBV DNA vaccine mediated by in vivo electroporation in chronic hepatitis B patients under lamivudine chemotherapy. J Viral Hepat. 2012;19:581-93.

148. Chen M, Li YG, Zhang DZ, Wang ZY, Zeng WQ, Shi XF, et al. Therapeutic effect of autologous dendritic cell vaccine on patients with chronic hepatitis B: a clinical study. World J Gastroenterol. 2005;11:1806-8.

149. Akbar SM, Furukawa S, Horiike N, Abe M, Hiasa Y, Onji M. Safety and immunogenicity of hepatitis B surface antigen-pulsed dendritic cells in patients with chronic hepatitis B. J Viral Hepat. 2011;18:408-14.

150. Luo J, Li J, Chen RL, Nie L, Huang J, Liu ZW, et al. Autologus dendritic cell vaccine for chronic hepatitis B carriers: a pilot, open label, clinical trial in human volunteers. Vaccine. 2010;28:2497-504.

151. Vandepapelière P, Lau GK, Leroux-Roels G, Horsmans Y, Gane E, Tawandee T, et al; Therapeutic HBV Vaccine Group of Investigators. Therapeutic vaccination of chronic hepatitis B patients with virus suppression by antiviral therapy: a randomized, controlled study of co-administration of HBsAg/ASO2 candidate vaccine and lamivudine. Vaccine. 2007;25:8585-97.

152. Maini MK, Boni C, Ogg GS, King AS, Reignat S, Lee CK, et al. Direct ex vivo analysis of hepatitis B virusspecific CD8 ${ }^{+} \mathrm{T}$ cells associated with the control of infection. Gastroenterology. 1999;117:1386-96.

153. Maini MK, Boni C, Lee CK, Larrubia JR, Reignat S, Ogg GS, et al. The role of virus-specific CD8 ${ }^{+}$cells in liver damage and viral control during persistent hepatitis B virus infection. J Exp Med. 2000;191:1269-80.

154. Akbar SM, Chen S, Al-Mahtab M, Abe M, Hiasa Y, Onji M. Strong and multi-antigen specific immunity by hepatitis B core antigen (HBcAg)-based vaccines in a murine model of chronic hepatitis B: HBcAg is a candidate for a therapeutic vaccine against hepatitis B virus. Antiviral Res. 2012;96:59-64. 
155. Betancourt AA, Delgado CA, Estévez ZC, Martínez JC, Ríos GV, Aureoles-Roselló SR, et al. Phase I clinical trial in healthy adults of a nasal vaccine candidate containing recombinant hepatitis B surface and core antigens. Int J Infect Dis. 2007;11:394-401.

156. Al-Mahtab M, Akbar SM, Aguilar JC, Uddin MH, Khan MS, Rahman S. Therapeutic potential of a combined hepatitis B virus surface and core antigen vaccine in patients with chronic hepatitis B. Hepatol Int. 2013;7:981-9.

157. Al Mahtab M, Akbar SMF, Aguilar JC, Guillen G, Penton E, Tuero A, et al. Treatment of chronic hepatitis $B$ naive patients with a therapeutic vaccine containing HBs and HBc antigens (a randomized, open and treatment controlled phase III clinical trial). PLoS One. 2018;13:e0201236.

158. Rivino L, Le Bert N, Gill US, Kunasegaran K, Cheng Y, Tan DZ, et al. Hepatitis B virus-specific T cells associate with viral control upon nucleos(t)ide-analogue therapy discontinuation. J Clin Invest. 2018;128:668-81. 